\title{
POLICY 'Let them choose not to eat cake...': Public health ethics, effectiveness and equity in government obesity strategy
}

\author{
Authors: John Coggon ${ }^{A}$ and Jean Adams ${ }^{B}$
}

\begin{abstract}
With a focus on obesity strategy, this paper examines and explains questions of ethics and equity in public health policy. We identify and explain the dynamics at play in assigning individual and social/political responsibility for health, in the context of policies that rely heavily on the exercise of individual agency. The paper builds on an earlier scientific study by one of the authors, expanding the analysis through reference to public health ethics, and social ethics more broadly.
\end{abstract}

KEYWORDS: Equity, health inequalities, obesity strategy, public health ethics, public health policy

DOI:10.7861/fhj.2020-0246

\section{Introduction}

Obesity policy requires considerations both of scientific insights and ethical values. Government strategy entails the balance of complex value judgments, and the engagement of expertise from disparate health and social science disciplines. The place of sciences may seem uncontroversial, capturing the need for evidence bases for example through data on nutritional epidemiology and people's decision-making. Ethical values may seem less apparent, but are also of fundamental importance: they are caught up in evaluations of ideas such as (personal and shared) responsibility, (meaningful) choice, and the legitimacy of interference with (institutional, commercial, and personal) freedoms. Just as the questions of public health sciences need to be addressed, so these questions of public health ethics must be tackled within debates on the formation and implementation of obesity policy.

In its most recent obesity strategy, published in the summer of 2020, the Department of Health and Social Care states that:

Tackling obesity is not just about an individual's effort, it is also about the environment we live in, the information we are given to

Authors: Aprofessor of law, Centre for Health, Law, and Society, University of Bristol Law School; ${ }^{B}$ senior lecturer in dietary public health, UKCRC Centre for Diet and Activity Research, MRC Epidemiology Unit, University of Cambridge School of Clinical Medicine make choices; the choices that we are offered; and the influences that shape those choices.

That's why when it comes to food and drink, we want to ensure everyone has the right information, that they are offered a fair deal and that they are not unduly influenced to purchase less healthy foods and drinks. Put simply, we want the healthy option to be an easier option for everyone.

The direction and impetus of this most recent obesity strategy reflects a change in the prime minister's approach. His current, more concerned outlook appears to follow directly from his own experience of severe COVID-19-related illness, which he and others have attributed to his own overweight status. This contrasts with his earlier statements on obesity policy, in which he derided and proposed to reverse the creep of the 'nanny state', for example through its use of 'sin taxes' on sugary products. ${ }^{2}$ Nevertheless, the public health community has been muted in its embrace of the strategy. Despite some progress away from a total reliance on individual responsibility, with proposals such as broader restrictions on food marketing, in line with the passage quoted above, Moore and Evans note that the latest strategy 'still emphasises individual willpower and personal responsibility in its promotion of a weight loss app and food labelling.'3

Between the impacts of austerity, measures whose effectiveness relies on the exercise of individual agency, and social and commercial factors and practices, the evidence clearly demonstrates socio-economic inequalities in the incidence of obesity in adults and children. This needs to be understood in a context of a broader worsening of health inequalities and the interrelationships between health inequalities and social (in)justice..$^{4-8}$

Neither recent obesity strategies, nor the current one, give cause for optimism about achieving substantial reductions in avoidable health inequalities. ${ }^{3,9}$ This is not to say that the strategy will have no impact. For example, recent modelling indicates that the commitment to banning television advertising of less healthy food and drinks before $9 \mathrm{pm}$ will decrease inequalities in childhood obesity. ${ }^{10}$ But if we just look to the 'moral mandates' of public health - mandates to protect and improve health and reduce health inequalities ${ }^{11,12}$ - there seems to be a clear basis to challenge many obesity policies on the grounds that they are likely to achieve inequitable effects. From a 'public health perspective', both they and their broader political context seem to ignore effective responses to health inequalities and how these have worsened since $2010 .{ }^{5}$ 
So, from a public health perspective the strategy may be lamented for not going far enough. However, a wholesale ethical evaluation of social policy cannot without argument assume that a public health perspective provides the right answer on what is equitable all things considered..$^{13}$ To explore a question of values and policy, we may be interested in health outcomes and inequalities (as opposed, say, to formally shared equality of opportunity, caught in a shrug of the shoulders and an observation that in principle everyone is free to exercise more and choose healthier food). But we cannot end an analysis with reference just to health outcomes unless we want to live in some sort of 'health theocracy.'14 Rather, we need to explore three things:

> What makes for a legitimate, fair, and mandated policy aim (recognising that doing nothing is itself a policy decision $\left.{ }^{15}\right)$ ?

> When realising policy aims, what ethical limitations do we face, looking both at constraints (eg protections of democratic values such as human rights) and questions of balancing the public's health against other policy aims?

> How should scientific evidence bases should be accounted for within these evaluations?

In what follows, we explore these questions of values and politics - of public health ethics - with reference to an influential paper that one of us (Adams) co-authored..$^{9}$ That paper asks a question of vital social importance: 'Why are some population interventions for diet and obesity more equitable and effective than others?' In answering the question, the paper scrutinises the effectiveness (or otherwise) of policy agendas such as the Change4Life health education programme. That is, Adams and colleagues look at measures that are rooted in questions of individual choice and hence responsibility. Their paper critiques measures that are ultimately effected (if at all) through individuals' personal decisionmaking; measures that, from a governmental and regulatory perspective, work through 'providing advice, guidance, and encouragement'.

\section{Conditions for individual agency-oriented public health interventions}

The following framing is based on the ethical analysis by Adams and colleagues, re-presented here with a list of four conditions for individuals' agency to be an effective means to achieve public health goals. In combination, these all must be met adequately if a policy or intervention is both meaningfully to be based on respect for individual agency and judged to be effective as a measure to protect or promote the public's health.

> Condition 1: A social and commercial environment that meaningfully provides healthy choices. People must be able to enjoy an environment within which healthy choices are actually and reasonably available (albeit within a context, by analysis, that also provides for or permits unhealthy choices).

> Condition 2: Autonomy. People must have decision-making capacity (as is assumed to be the case for all adults but potentially raising distinct assumptions regarding children).

> Condition 3: Motivated engagement. Individuals must be 'motivated to engage with advice, guidance, and encouragement.' ${ }^{9}$ If health outcomes and disparities are to be changed, this also requires that sufficient (however that is measured) numbers of people across all of society are motivated to act on that engagement in favour of health.
> Condition 4: Actual deliberation. Individuals must not just formally be free to choose, but must reasonably be expected to deliberate: in real terms, is choice being exercised (as opposed, for instance, to the exercise of a non-deliberative response to the environment within which an apparent choice is being made $\left.{ }^{16}\right)$ ?

Read against these four conditions, Adams and colleagues demonstrate how policy agendas that rely (predominantly) on individuals making healthy choices through 'agentic' deliberation are problematic. In the paper, the problem is framed with specific reference to "the twin public health aims of preventing disease and minimising inequalities. ${ }^{9}$ That is, it is framed by reference to the public health perspective on ethics, as explained above. Crucially, Adams and colleagues conclude that 'high agency' interventions, while potentially sound parts of a public health strategy, are poor when used as a comprehensive, or the predominant, approach. They are likely to be less effective and they have the potential to be more inequitable across socio-economic groups than alternatives that include lower agency approaches. ${ }^{17,18}$ This may be because the personal financial and time resources required to enact individual agency are less available to people living in less affluent circumstances. ${ }^{19}$ For example, less affluent parents find it harder to support their children to take part in organised sports than their more affluent counterparts because they lack the material resources for uniforms and equipment, and the time to take children to practice. ${ }^{20}$ Key here is that a predominant focus on the (proper) presumption of the universality (at least for adults) of condition 2 - decision-making capacity - detracts attention from the ethical and practical significance of conditions 1,3 , and 4 .

\section{The roles of social actors and agencies, and health as a motivating value}

Because significant shortcomings can be shown, in terms of health outcomes and equity, where policy measures rely significantly on individuals' exercise of agency, Adams and colleagues' paper considers the roles of other actors and the use of lower-agency interventions. Examples of obesity strategies that require less individual agency include taxes on sugary drinks, restrictions on advertising of less healthy foods, and planning controls on where new takeaway outlets can open. These are all hypothesised to achieve their effects not through deliberative mechanisms whereby consumers weigh up information on risks and benefits and make informed 'choices', but by changing the fiscal, social and physical environment in which individuals live so that the healthier options become not just easier, but the default. ${ }^{20}$ Of particular note is the role of government, of the public conceived as a collective, and of food companies. This again invites an analysis of ethical questions and consideration of the role of scientific evidence bases and social and political values beyond those found in a public health perspective. ${ }^{21,22}$

\section{Health as a motivating value, and the aims of policy}

The conclusion that we, as a society, ought to move to loweragency strategies can only be reached if we accept that health is itself rightly the (or at least a) predominant value. In presenting the four conditions for effective individual agency above, we saw the importance of individuals' motivation (condition 3). This is a question of value. A comparable question of value must arise too if we look at health from a societal perspective and aim to rationalise 
and justify low-agency policy measures. At the same time, if we consider (for example) health impact assessments ${ }^{23}$ or health in all policies approaches, ${ }^{24}$ we may be keen to argue that actual deliberation on health is needed (in equivalence with condition 4).

Some theories in public health ethics are founded on the perspective that health should be considered the basic capability on which human flourishing is founded, and thus the ultimate priority of government ${ }^{7,25}$ Other theories build on the importance of health, but as one of various values that government should protect and promote. ${ }^{6,26}$ And of course there are positions that argue against health as a legitimate socio-political value. ${ }^{27,28}$ From an ethical perspective, when we consider health as one of various values we have to recognise that there is work to do not just in establishing that it is important in policy agendas, but also that its relative weight, when balanced against other factors, must be considered. ${ }^{29}$

This means that our ethical analysis of policy should not just account for whether health is a vital social value, but also how it is this. Health matters. What else does, and how should these things be weighted and weighed against one another? Such questions require an explicit exercise that explains how different social values are identified, weighted, and balanced.

\section{High-agency, low-agency, and justifying the means of effecting policy}

As well as explaining the (relative) importance of health and health equity as policy aims, it is necessary to consider questions of what lends ethical legitimacy to different forms or methods of intervention. Adams and colleagues address this through their discussion of the 'acceptability' of low-agency interventions to parties including 'politicians, who may enact interventions; the public, who are the recipients of interventions, and food companies, whose commercial interests may be affected by interventions. ${ }^{.9}$ The paper expressly notes and challenges the idea that the acceptability of low-agency population interventions may be grounded on claims about disrespecting free choice (explained by reference to conditions 1, 2, and 4): some 'choices' are not available to all, eg because of prohibitive cost, and many behaviours are not the product of meaningful deliberation. They also rightly note that freedom of choice, as a value, is not exhaustive of all values, and in particular that the importance of the public's health is also important: so even where conditions 1, 2, and 4 are met, it does not follow without analysis that a person's choice ought to be vindicated.

Nevertheless, within ethical evaluation of public health policy, attention must be given to what makes different forms of intervention acceptable. Important values and processes born of democratic principles and freedoms must be considered as necessary and legitimate side-constraints on policy. For example, a sound political and legal mandate is required for government intervention; policies need to be human rights compliant; and all policies are implemented in contexts of limited resources. In addition, as noted by Adams and colleagues, account also needs to be given to the reality that there may be actors, such as powerful industrial organisations with entrenched financial interest and (often) significant political influence, advocating against effective public health interventions. ${ }^{32-36}$

A consequence of these considerations is that the best interventions, in terms of health outcomes and equity, will not always be acceptable: sometimes other considerations will rightly take precedence. This may be because precedence is given to alternative substantive values (eg economic freedom), the measure is considered disproportionate (eg a disproportionate interference with liberty), or a need for procedural considerations has to be met (eg a power created to effect a particular measure). ${ }^{31,32}$ At the same time, the best interventions may be impeded by matters that are not legitimate (eg given conflicts of interest, unwarranted scope for political influence). ${ }^{32}$ An important aspect of ethical public health policy is reflective consideration of constraints on, as well as motivations for, effective and equitable public health outcomes. ${ }^{37}$

\section{Conclusions}

Adams and colleagues say that: 'The obvious assumption of [programmes such as Change $4 \mathrm{Life}$ ] is that advice, guidance, and encouragement will change the population's diet and activity behaviours. ${ }^{9}$ That is an obvious assumption, and on Adams and colleagues' analysis it holds true. However, their paper also shows that programmes that rely on high levels of individual agency are likely to have a limited impact on the public's health when compared with what could be achieved through alternative, more structural, measures. Furthermore, insofar as the health impacts of higher agency interventions are real, they have the potential to compound inequalities in health between social groups.

Through the points raised in this paper, we would invite debate of whether such programmes are satisfactory from an ethical perspective; whether and why it would be equitable to go further, in terms of being 'more interventionist', or even indeed inequitable not to do so. We have explained the importance of identifying how and why health is a value that should motivate policy aims. We have also explained how such points need to be contextualised against democratic values and constraints that might enable, and might constrain, public health policy agendas: for example, the proper provision of a legal mandate to act, or considerations regarding due respect for human rights.

Alongside establishing a scientific evidence base, questions of value are central to a rigorous idea of public health that can stand on its moral base. 14,22,23 Inevitably, we need to account for dominant socio-political realities, including the motivations and interests of political actors. ${ }^{38}$ But overall, consistent with the aims expressed in Adams and colleagues' paper to win 'hearts and minds, ${ }^{9}$ we need to place public health values alongside others and measure success and failure in that context. An in-the-round evaluation of the values and agency of individuals, different publics, and governmental and other actors must be at the core of interventions for more equitable and effective public health intervention strategies.

\section{Acknowledgements}

We would like to thank Yoav Ben-Shlomo, who provided the impetus for developing the analysis in this paper.

\section{Funding}

JC's contribution to this work was made possible by the Tackling Root Causes Upstream of Unhealthy Urban Development consortium, award reference: MR/S037586/1, supported by the UK Prevention Research Partnership, which is funded by the British Heart Foundation, Cancer Research UK, Chief Scientist Office of 
the Scottish Government Health and Social Care Directorates, Engineering and Physical Sciences Research Council, Economic and Social Research Council, Health and Social Care Research and Development Division (Welsh Government), Medical Research Council, National Institute for Health Research, Natural Environment Research Council, Public Health Agency (Northern Ireland), The Health Foundation and the Wellcome Trust. JA's contribution to this work was supported by the Medical Research Council MC_UU_12015/6. JA is supported by the Centre for Diet and Activity Research, a UKCRC funded centre of public health research excellence; funding from Cancer Research UK, British Heart Foundation, Economic and Social Research Council (grant number ES/G007462/1), Medical Research Council (grant number MR/K023187/1), National Institute for Health Research, and Wellcome Trust (grant number $087636 / 2 / 08 / Z$ ) is gratefully acknowledged.

\section{References}

1 Department of Health and Social Care. Tackling obesity: empowering adults and children to live healthier lives. Available from www. gov.uk/government/publications/tackling-obesity-governmentstrategy/tackling-obesity-empowering-adults-and-children-to-livehealthier-lives\#what-next [Accessed 27 July 2020].

2 Rayner G. Boris Johnson aims to put end to the 'nanny state' and its 'sin taxes' on food. The Telegraph, 2 July 2019. www.telegraph. co.uk/politics/2019/07/02/boris-johnson-aims-put-end-nanny-statesin-taxes-food/.

3 Moore JB, Evans CEL. Obese and hungry: two faces of a nation. BM] 2020;370:m3084

4 Marmot M, Allen J, Goldblatt P et al. Fair society, healthy lives: The Marmot Review. The Marmot Review, 2010.

5 Marmot M, Allen J, Boyce T et al. Health equity in England: The Marmot Review 10 years on. Health Foundation, 2020.

6 Powers M, Faden R. Social justice: The moral foundations of public health and health policy. Oxford University Press, 2006.

7 Ruger JP. Health and social justice. Oxford University Press, 2010.

8 Venkatapuram S. Health justice: an argument from the capabilities approach. Polity Press, 2011.

9 Adams J, Mytton O, White M, Monsivais P. Why are some population interventions for diet and obesity more equitable and effective than others? The role of individual agency. PLOS Medicine 2016;13:e1001990.

10 Mytton O, Boyland E, Adams ] et al. The potential health impact of restricting less-healthy food and beverage advertising on UK television between 05.30 and 21.00 hours: A modelling study. PLOS Medicine 2020;17:e1003212.

11 Coggon J, Viens AM. Public health ethics in practice: An overview of public health ethics for the UK Public Health Skills and Knowledge Framework. Public Health England, 2017.

12 Coggon J, Tahzib F. 'The science of social justice': assuring the conditions for ethics and equity at the heart of public health. J Public Health 2020;2020:fdaa021.

13 Coggon J. What makes health public? Cambridge University Press, 2012.

14 Jennings B. Community in public health ethics. In: Ashcroft R, Dawson A, Draper H, John McMillan J (eds.), Principles of Health Care Ethics (2nd edn). Wiley, 2007.

15 Nuffield Council on Bioethics. Public health: Ethical issues. Nuffield Council on Bioethics, 2007.

16 Yeung K. Nudge as fudge. Modern Law Review 2012;75:122-48.
17 Hillier-Brown FC, Bambra CL, Cairns J-M et al. A systematic review of the effectiveness of individual, community and societal-level interventions at reducing socio-economic inequalities in obesity among adults. Int J Obesity 2014;38:1483-90.

18 Hillier-Brown FC, Bambra CL, Cairns J-M et al. A systematic review of the effectiveness of individual, community and societal level interventions at reducing socioeconomic inequalities in obesity amongst children. BMC Public Health 2014;11:834

19 Marteau TM, Rutter H, Marmot M. Changing behaviour: an essential component of tackling health inequalities. BMJ 2021;372:n332.

20 Hardy LL, Kelly B, Chapman K et al. Parental perceptions of barriers to children's participation in organised sport in Australia. J Paediatr Child Health 2010;46:4:197-203.

21 Coggon J. Smoke Free? Public health policy, coercive paternalism, and the ethics of long-game regulation. J Law Society 2020;47: $121-48$.

22 Coggon J. The nanny state debate: A place where words don't do justice. Faculty of Public Health, 2018.

23 World Health Organization. The Helsinki Statement on Health in All Policies. WHO, 2014.

24 World Health Organization. Health impact assessment. www.who. int/health-topics/health-impact-assessment.

25 Gostin LO, Wiley LF. Public health law: power, duty, restraint. Third edition. University of California Press, 2016.

26 Wolff J, de-Shalit A. Disadvantage. Oxford University Press, 2007.

27 Skrabanek P. The death of humane medicine: and the rise of coercive healthism. Social Affairs Unit, 1994.

28 Metzel JM, Kirkland A (eds.). Against health: how health became the new morality. New York University Press, 2010.

29 Pugh J. Coercive paternalism and back-door perfectionism. J Med Ethics 2014:40:350-1.

30 Gostin L, Monahan ], Kaldor ] et al. The legal determinants of health: harnessing the power of law for global health and sustainable development. Lancet 2019;393,1857-910.

31 Coggon J. Legal, moral and political determinants within the social determinants of health: approaching transdisciplinary challenges through intradisciplinary reflection. Public Health Ethics 2020;13:141-7.

32 Raphael D. Beyond policy analysis: the raw politics behind opposition to health public policy. Health Promot Int 2015;30:380-96.

33 Scally $\mathrm{G}$. Whose behaviour needs to change? Key factors in an effective response to the burden of non-communicable disease. Social Business 2017;7:279-91.

34 Schrecker T. Was Mackenbach right? Towards a practical political science of redistribution and health inequalities. Health Place 2017:46:293-9.

35 Greer SL, Bekker M, Leeuw E et al. Policy, politics and public health. Eur J Public Health 2017;27:40-3.

36 McKee M, Stuckler D. Revisiting the corporate and commercial determinants of health. Am J Public Health 2018:108:1167-70.

37 Coggon J, Gostin LO. The two most important questions for ethical public health. J Public Health 2020;42:198-202.

38 Gornall J. Big tobacco, the new politics, and the threat to public health. BMJ 2019;365:I2164.

Address for correspondence: Professor John Coggon, Centre for Health, Law, and Society, University of Bristol Law School, 8-10 Berkeley Square, Bristol, BS8 1HH, UK.

Email: John.Coggon@bristol.ac.uk

Twitter: @CHLSBristol 